\title{
Improving patient-centred care for rheumatoid arthritis
}

\author{
Nick Bansback PhD, Kam Shojania MD, Diane Lacaille MD MHSc
}

$\mathrm{B}$ iologic drugs are well-known for both revolutionizing the treatment of rheumatoid arthritis and their high costs. ${ }^{1}$ Recently, a randomized noninferiority trial, partly funded and conducted in Canada, showed that an alternative treatment for rheumatoid arthritis comprising older agents can be just as clinically effective, is associated with fewer serious adverse effects and is 20 times less expensive than treatment with a biologic. ${ }^{2}$ The Rheumatoid Arthritis Comparison of Active Therapies (RACAT) trial strengthened existing evidence on the efficacy of a combination of three drugs known as triple therapy..$^{2-4}$ Greater use of triple therapy could have a large impact on patient outcomes and health care costs; however, it is infrequently offered or prescribed before a biologic drug to patients with rheumatoid arthritis.

Guidelines recommend that patients with rheumatoid arthritis receive conventional disease-modifying antirheumatic drugs (DMARDs), beginning with methotrexate. ${ }^{5}$ More than 20 years ago, triple therapy, a combination of methotrexate and the other DMARDs, sulfasalazine and hydroxychloroquine, was found to be substantially more effective than methotrexate alone, and it costs less than $\$ 1000$ per year per patient. ${ }^{6}$

In patients for whom conventional DMARDs do not work, biologics have emerged as an alternative. These drugs target either tumour necrosis factor (adalimumab, certolizumab pegol, etanercept, golimumab, and infliximab) or other cytokines or cells (abatacept, anakinra, rituximab and tocilizumab). Nine biologics are available for treating rheumatoid arthritis, all of which are superior to methotrexate alone and cost about $\$ 20000$ per year. ${ }^{1}$

The RACAT trial (blinded, with etanercept) is the third head-to-head trial to have found triple therapy to be noninferior to biologics in reducing disease activity, but it is the first double-blind trial to evaluate patients in whom conventional DMARDs have not worked. ${ }^{2}$ All trials found higher rates of mild adverse effects with triple therapy and higher rates of serious infections and death with biologics. ${ }^{2-4}$ Although the RACAT trial found no statistically significant difference in radiographic progression, both the Swefot (Swedish Farmacotherapy) (unblinded, with infliximab) ${ }^{3}$ and TEAR (Treatment of Early Aggressive Rheumatoid Arthritis) (blinded, with etanercept $)^{4}$ trials found that radiographic progression was significantly lower on average with biologics. However, the average difference was driven by a small subset of patients: in Swefot, about $25 \%$ of patients had no radiographic progression while taking either therapy; among the remainder, the difference between triple therapy versus and biologics was not clinically relevant in $90 \%$ of the patients.

Neither triple therapy nor biologics are effective in all patients. In the RACAT trial, an equal proportion of patients in each group (about 27\%) switched treatments after 24 weeks owing to lack of efficacy. ${ }^{2}$ Benefit was seen in both groups with the alternate therapy - that is, nonresponders to triple therapy switching to biologics, and nonresponders to biologics switching to triple therapy.

Currently, fewer than $25 \%$ of patients with rheumatoid arthritis try triple therapy before biologics. ${ }^{7,8}$ This is not surprising, given that guidelines for rheumatoid arthritis recommend biologics only after conventional DMARD failure and do not mention triple therapy specifically. ${ }^{5}$ In Canada, most health insurance programs require DMARD combination therapy before biologics, but only one program requires triple therapy specifically. Timing may explain this: the first trial showing triple therapy's superiority over methotrexate was published in 1996, ${ }^{6}$ shortly before biologics became available. By the time follow-up trials confirmed tri-

\section{KEY POINTS}

- Recent studies have found that triple therapy - methotrexate, sulfasalazine and hydroxychloroquine - is as effective as biologics for treating rheumatoid arthritis and has fewer serious adverse effects.

- Currently, only one of four patients trials triple therapy before using a biologic.

- Because triple therapy costs substantially less than a biologic, a policy to increase the use of triple therapy is supported by both clinical and economic arguments.

- A patient-centred approach, through which patients are informed of the options and offered the choice between triple therapy and a biologic, is key. 
ple therapy's efficacy, biologics were being marketed with the intensity of any breakthrough product.

Accumulated evidence that triple therapy and biologics can be equally clinically effective (although it is unknown which therapy will be best for a given patient) should have clear implications for policy and practice. Because biologics can cost 20 times more than triple therapy, the clinical argument for using the latter before biologics seems to make economic sense.

A potential health policy response would be to include triple therapy in provincial drug formularies and require it before biologics. However, if patients and physicians are forced to use an unwanted therapy, they may try to find a way around the formulary (e.g., by claiming medication intolerance). Furthermore, requiring triple therapy before a biologic frames the former as the means to accessing a biologic and not as a promising treatment option in and of itself.

Poor knowledge dissemination may explain why, until now, triple therapy has been perceived as less desirable than biologics. Furthermore, there may be discordance between what doctors think their patients want and what their patients really want. ${ }^{9}$ It is preferable for patients and clinicians to choose their preferred treatment together and willingly, with full knowledge of the facts. Rheumatologists are reportedly concerned about the acceptability to patients of triple therapy's multiple daily pills and increased mild adverse effects. ${ }^{10}$ However, in a study of patients' attitudes about combination therapy, most patients were less concerned about taking multiple pills and viewed treatment benefits as outweighing adverse effects. ${ }^{11}$

We believe that with careful shared decision-making, more patients with rheumatoid arthritis would choose triple therapy. This patient-centred approach would allow patients to compare treatment attributes and choose treatment based on personal preferences. ${ }^{9,12}$ For example, patients should know that biologics can take effect more quickly and are received weekly or monthly by injection or infusion; that triple therapy requires daily pills; that biologics carry a higher risk of serious adverse effects and possibly death and triple therapy has a higher risk of mild ones; and that biologics cost much more than triple therapy.

Greater empowerment of patients with rheumatoid arthitis to participate in treatment decisions could contribute to triple therapy being used more often. If $80 \%$ of patients chose to try triple therapy before biologics, we calculate that at least $\$ 25$ million a year would be saved in Canada ${ }^{8}$ Under a rheumatologist's care, patients who do not improve with triple therapy could be swiftly switched to a biologic. Patients are recognizing their right to shared decisionmaking; let's promote this approach for rheumatoid arthritis.

\section{References}

1. Singh JA, Christensen R, Wells GA, et al. A network metaanalysis of randomized controlled trials of biologics for rheumatoid arthritis: a Cochrane overview. CMAJ 2009;181:787-96.

2. O'Dell JR, Mikuls TR, Taylor TH, et al. Therapies for active rheumatoid arthritis after methotrexate failure. N Engl J Med 2013;369: 307-18.

3. van Vollenhoven RF, Geborek P, Forslind K, et al.; Swefot study group. Conventional combination treatment versus biological treatment in methotrexate-refractory early rheumatoid arthritis: 2 year follow-up of the randomised, non-blinded, parallel-group Swefot trial. Lancet 2012;379:1712-20.

4. Moreland LW, O'Dell JR, Paulus HE, et al. A randomized comparative effectiveness study of oral triple therapy versus etanercept plus methotrexate in early aggressive rheumatoid arthritis: the treatment of early aggressive rheumatoid arthritis trial. Arthritis Rheum 2012;64:2824-35.

5. Bykerk VP, Akhavan P, Hazlewood GS, et al.; Canadian Rheumatology Association. Canadian Rheumatology Association recommendations for pharmacological management of rheumatoid arthritis with traditional and biologic disease-modifying antirheumatic drugs. J Rheumatol 2012;39:1559-82.

6. O'Dell JR, Haire CE, Erikson N, et al. Treatment of rheumatoid arthritis with methotrexate alone, sulfasalazine and hydroxychloroquine, or a combination of all three medications. N Engl J Med 1996;334:1287-91.

7. Ng B, Chu A, Khan MM. A retrospective cohort study: 10-year trend of disease-modifying antirheumatic drugs and biological agents use in patients with rheumatoid arthritis at Veteran Affairs Medical Centers. BMJ Open 2013;3:e002468.

8. Bansback N, Lacaille DV, Guh D, et al. Economic implications for policies regarding triple therapy use in patients with rheumatoid arthritis. Arthritis Rheumatol 2014;66:S502.

9. Mulley AG, Trimble C, Elwyn G. Stop the silent misdiagnosis: patients' preferences matter. BMJ 2012;345:e6572.

10. Fraenkel L, Miller AS, Clayton K, et al. When patients write the guidelines: patient panel recommendations for the treatment of rheumatoid arthritis. Arthritis Care Res (Hoboken) 2016;68:26-35.

11. van Tuyl LH, Plass AM, Lems WF, et al. Discordant perspectives of rheumatologists and patients on COBRA combination therapy in rheumatoid arthritis. Rheumatology (Oxford) 2008;47:1571-6.

12. Barry MJ, Edgman-Levitan S. Shared decision making — pinnacle of patient-centered care. $N$ Engl J Med 2012;366:780-1.

Affiliations: School of Population and Public Health (Bansback); Division of Rheumatology (Shojania, Lacaille), University of British Columbia; Centre for Health Evaluation and Outcome Sciences (Bansback, Shojania), St Paul's Hospital, Vancouver; Arthritis Research Canada (Bansback, Shojania, Lacaille), Richmond, BC.

Contributors: Nick Bansback conceived this manuscript. Nick Bansback, Diane Lacaille and Kam Shojania all contributed to the writing of the manuscript. All authors read and approved the final manuscript. Each authors approved the final version and agrees to act as guarantor for the work.

Acknowledgements: The authors thank Stephanie Harvard for her editorial assistance. Nick Bansback is a CIHR (Canadian Institutes of Health Research) New Investigator. Diane Lacaille holds the Mary Pack Arthritis Chair in rheumatology research from The Arthritis Society of Canada and the University of British Columbia.

Funding: The Canadian Initiative for Outcomes in Rheumatology, a granting organization through the Canadian Rheumatology Association, supported work related to this paper. 